\title{
The Effect of Amlodipine Combined with Atorvastatin on the Levels of HMGB-1 and YKL-40 in Patients with Coronary Heart Disease and Carotid Atherosclerosis
}

\author{
H. F. DONG AND CHENG Al ${ }^{1 *}$ \\ Department of Cardiovascular Medicine, 'Department of Medicine, Yuyao People's Hospital, Ningbo 315400, Zhejiang Province, \\ China
}

Dong et al.: Effect of Amlodipine Combined with Atorvastatin

\begin{abstract}
To observe the incidence of adverse reactions of amlodipine combined with atorvastatin in patients with coronary heart disease complicated with carotid atherosclerosis and the effect on the levels of high-mobility group box protein 1 and human cartilage glycoprotein 39. Retrospective analyses of patients with coronary heart disease combined with carotid atherosclerosis in our hospital are divided into two groups according to different treatment methods. The control group was given atorvastatin and the observation group was given amlodipine on this basis. The differences in blood lipid levels, myocardial enzyme levels, intima-media thickness levels, high-mobility group box protein 1 and human cartilage glycoprotein 39 changes before and after treatment were compared between the two groups. During the treatment period, there was no difference in the incidence of complications between the two groups. There was no difference in blood lipid levels between the two groups before treatment. After treatment, the levels of low-density lipoprotein cholesterol, triglycerides and total cholesterol in the observation group were lower than those in the control group and the levels of high-density lipoprotein cholesterol were higher than those in the control group. There was no difference in intima-media thickness before treatment between the two groups. At 4 and 8 w after treatment, the intima-media thickness value of the observation group was lower than that of the control group ( $p<0.05)$. There was no difference in the levels of high-mobility group box protein 1 and human cartilage glycoprotein 39 between the two groups before treatment. After treatment, the levels of high-mobility group box protein 1 and human cartilage glycoprotein 39 in the observation group were lower than those in the control group $(p<0.001)$. There was no difference in myocardial enzyme indexes between the two groups before treatment. After treatment, the levels of lactate dehydrogenase and creatine kinase myocardial band of the two groups were lower than before treatment and the observation group was lower than the control group, the difference was statistically significant $(\mathbf{p}<\mathbf{0 . 0 0 1})$. Amlodipine combined with atorvastatin has a good therapeutic effect on patients with coronary heart disease complicated with carotid atherosclerosis and has good application value.
\end{abstract}

Key words: Coronary heart disease, atherosclerosis, atorvastatin, cytokines

Coronary Heart Disease (CHD) is an ischemic heart disease caused by coronary atherosclerosis ${ }^{[1]}$. The incidence of carotid atherosclerosis increases with age. In the early stage of carotid atherosclerosis, intimal thickening occurs first and when the condition worsens, carotid atherosclerotic plaques are formed ${ }^{[2]}$. Intraplaque hemorrhage, plaque rupture and detachment and wall thrombosis are all risk factors for the worsening of the disease ${ }^{[3]}$. At present, there are many drugs for the treatment of carotid atherosclerosis in clinic and combined treatment is a better plan ${ }^{[4]}$. The study found the combined use of atorvastatin and amlodipine can enhance the lipid-lowering effect and protect the function of the heart and brain ${ }^{[5]}$. The level of myocardial enzyme spectrum can accurately reflect the degree of myocardial ischemic damage and the permeability of the cell membrane, so its level is measured. It plays an important role in the diagnosis of CHD, condition judgment and prognosis evaluation and evaluation of treatment effect ${ }^{[6]}$. This study observed the efficacy of atorvastatin combined with amlodipine in the treatment of CHD with carotid atherosclerosis, and tested its effect on myocardial enzyme levels and High-Mobility Group Box Protein 1 (HMGB-1) and the impact of Human Cartilage Glycoprotein 39 (YKL-40) levels. 
YKL-40 is a newly discovered serum inflammatory marker in recent years. Recent studies have pointed out that it is involved in the formation of atherosclerosis. In recent years, studies have found that HMGB-1 can promote Nuclear Factor Kappa B (NF- $\mathrm{B}$ ) in cells. Signal transduction, overexpressed in macrophages in atherosclerosis ${ }^{[7]}$. Studies have shown that the expression levels of YKL-40 and HMGB-1 in patients with diabetes and CHD are significantly higher than those in patients with simple diabetes ${ }^{[8]}$. The combined use of atorvastatin and amlodipine can enhance the lipid-lowering effect and protect the heart and brain functions. It also has a good effect in the treatment of CHD complicated with carotid atherosclerosis ${ }^{[9]}$. This study speculates that this combined regimen may improve the body's inflammatory response. At present, there are few studies on the effect of this treatment regimen on serum YKL-40 and HMGB-1 levels in patients with $\mathrm{CHD}$ and carotid atherosclerosis. There is no relevant research at this time and the research is based on this.

\section{MATERIALS AND METHODS}

\section{Research objects information:}

A retrospective analysis of patients with CHD and carotid atherosclerosis who were treated in our hospital from June 2018 to October 2019 was selected. Inclusion criteria: Adults; those who meet the diagnostic criteria of $\mathrm{CHD}^{[10]}$ and have carotid atherosclerosis on ultrasound; those who have no other serious diseases. Exclusion criteria: Patients with incomplete clinical data; patients with immune dysfunction. According to the standard, a total of 80 cases were included, including 40 cases in the control group, 26 males and 14 females, aged 50-68 y old, with an average of $57.65 \pm 4.12$ y old; 40 cases in the observation group, 22 males and 18 females, aged $58-69$ y old, with an average of $57.71 \pm 5.08 \mathrm{y}$ old. There was no difference in general information such as age and gender between the two groups of patients and they were comparable. This study was reviewed and approved by the ethics committee and the patients gave informed consent.

\section{Research methods:}

Control group was given basic treatment, patients take atorvastatin tablets (produced by Guangdong Baike Pharmaceutical Co., Ltd., National Medicine Standard: H20120021) orally once a day and the dosage according to the patient's condition is $10-20 \mathrm{mg}$, once a day, continuously taken for 7-9 w. Observation group was given amlodipine (Shihuida Pharmaceutical
Group, Specification: $2.5 \mathrm{mg} /$ tablet, National Medicine Standard H19991083) was added to the basic treatment. The dosage according to the patient's condition is 2.5-5 $\mathrm{mg}$ daily. Take it once for 7-8 w.

\section{Evaluation index:}

Observe the incidence of adverse reactions in the two groups of patients and compare the differences in the changes in blood lipid levels, Intima-Media Thickness (IMT) levels, HMGB-1 and YKL-40 between the two groups before and after treatment.

Before and after treatment, $3 \mathrm{ml}$ of fasting venous blood was collected from the patient, centrifuged $(2000 \mathrm{r} / \mathrm{min}$, $15 \mathrm{~min}$ ) and the serum was separated. The serum was stored in a refrigerator at $-80^{\circ}$ for testing; Triglycerides (TG), Total Cholesterol (TC), High-Density Lipoprotein Cholesterol (HDL-C) and Low-Density Lipoprotein Cholesterol (LDL-C) levels were detected using Hitachi 7179 automatic analyzer detection. Chemiluminescence method was used to detect serum Lactate Dehydrogenase (LDH) and Creatine Kinase Myocardial Band (CK-MB) levels. The instrument used was Beckman Coulter AU5800 automatic biochemical analyzer and found values of $\mathrm{LDH}$ (normal reference value $\leq 252 \mathrm{U} / 1$ ), CK-MB (normal reference value $<0.6$ $\mathrm{ng} / \mathrm{ml})$.

Detect the contents of YKL-40 and HMGB-1 by Enzyme-Linked Immunosorbent Assay (ELISA) method and operate according to the ELISA kit (American IND company) instructions. First configure the standard products as required and determine the Optical Density (OD) of each well of the standard product under the microplate reader (American Thermo company). Use the professional software "CurveExpert 1.3 " to make the standard curve with the concentration of the standard substance as the ordinate and the OD value as the abscissa. Then prepare the sample to be tested according to the requirements, set the concentration gradient, set up 3 parallel holes for each concentration, test the OD value of each well of the sample to be tested under the same conditions and take the average of the OD values of the parallel holes as the final measurement data, substituting the average OD value of the sample to be tested at each concentration into the regression equation of the standard curve, read the concentration of resistin and adiponectin in the sample.

IMT detection: Use Siemens Acuson S2000 color Doppler ultrasonic detector, the probe frequency is $8.0 \sim 11.0 \mathrm{mHz}$. The patient is placed in a supine position and the head is turned to the opposite side to be checked, 
so that the neck is fully exposed, and the head and neck are stretched as far as possible to maintain stability, breathing, tilt the head to the other side, check from the medial end of the clavicle and obtain two-dimensional images of the horizontal and vertical common carotid arteries from the front, middle and back of the neck. There are two lines in longitudinal ultrasound imaging. The line between the inner membrane and the lumen is the inner line, and the line between the media and the adventitia is the outer line. The vertical distance between them is IMT. The other side is also performed in the same way. For detection, each side was measured three times and the average value of the six measurements was taken as the average IMT $^{[11]}$.

\section{Statistical analysis:}

Use Statistical Package for the Social Sciences (SPSS) 20.0 software to analyze. Counting and measurement data are expressed as examples and mean \pm standard deviation, respectively. Use $t$ test and chi-square test for statistical analysis, $\mathrm{p}<0.05$ indicates that the difference is statistically significant.

\section{RESULTS AND DISCUSSION}

The incidence of adverse reactions between the two groups of patients is compared. During the treatment period, there were 2 cases of gastrointestinal reactions in the control group, 1 case of liver and kidney function abnormalities, 1 case of gastrointestinal reactions in the observation group, and 0 cases of liver and kidney function abnormalities. There was no difference in the incidence of complications between the two groups.

Blood lipid levels between the two groups of patients before and after treatment were compared. Table 1 show that there was no difference in blood lipid levels between the two groups before treatment. After treatment, the levels of LDL-C, TG and TC in the observation group were $(2.02 \pm 0.42) \mathrm{mmol} / \mathrm{l},(1.16 \pm 0.31) \mathrm{mmol} / \mathrm{l},(3.57)$ $\pm 0.82) \mathrm{mmol} / \mathrm{l}$, lower than the control group, HDL-C level is $(1.65 \pm 0.39) \mathrm{mmol} / \mathrm{l}$, higher than the control group.

IMT levels between the two groups of patients before and after treatment were compared. Table 2 shows that there is no difference in IMT between the two groups of patients before treatment. 4 and $8 \mathrm{w}$ after treatment, the IMT values of the observation group were $(1.16 \pm 0.11)$ $\mathrm{mm}$ and $(1.10 \pm 0.11) \mathrm{mm}$, which were lower than those of the control group $(\mathrm{p}<0.05)$.

The levels of HMGB-1 and YKL-40 between the two groups of patients before and after treatment were compared. Table 3 shows that there was no difference in the levels of HMGB-1 and YKL-40 between the two groups of patients before treatment. After treatment, the levels of HMGB-1 and YKL-40 in the observation group were lower than those in the control group $(\mathrm{p}<0.001)$.

Myocardial enzyme indexes before and after treatment between the two groups was compared. Table 4 shows that there was no difference in myocardial enzyme indexes between the two groups of patients before treatment. After treatment, the levels of LDH and CK$\mathrm{MB}$ of the two groups were lower than those before treatment and the observation group was lower than that of the control group. The difference was statistically significant $(\mathrm{p}<0.001)$.

TABLE 1: COMPARISON OF BLOOD LIPID LEVELS BETWEEN THE TWO GROUPS OF PATIENTS BEFORE AND AFTER TREATMENT

\begin{tabular}{lcccccccc}
\hline \multirow{2}{*}{ Group } & \multicolumn{2}{c}{ LDL-C $(\mathrm{mmol} / \mathrm{l})$} & \multicolumn{2}{c}{$\mathrm{HDL}-\mathrm{C}(\mathrm{mmol} / \mathrm{l})$} & \multicolumn{2}{c}{$\mathrm{TG}(\mathrm{mmol} / \mathrm{l})$} & \multicolumn{2}{c}{$\mathrm{TC}(\mathrm{mmol} / \mathrm{l})$} \\
\cline { 2 - 8 } & $\begin{array}{c}\text { Before } \\
\text { therapy }\end{array}$ & $\begin{array}{c}\text { After } \\
\text { treatment }\end{array}$ & $\begin{array}{c}\text { Before } \\
\text { therapy }\end{array}$ & $\begin{array}{c}\text { After } \\
\text { treatment }\end{array}$ & $\begin{array}{c}\text { Before } \\
\text { therapy }\end{array}$ & $\begin{array}{c}\text { After } \\
\text { treatment }\end{array}$ & $\begin{array}{c}\text { Before } \\
\text { therapy }\end{array}$ & $\begin{array}{c}\text { After } \\
\text { treatment }\end{array}$ \\
\hline $\begin{array}{l}\text { Control } \\
\text { group }\end{array}$ & $2.85 \pm 0.62$ & $2.24 \pm 0.55$ & $1.36 \pm 0.49$ & $1.48 \pm 0.25$ & $1.51 \pm 0.43$ & $1.34 \pm 0.45$ & $4.62 \pm 1.11$ & $4.10 \pm 1.03$ \\
$\begin{array}{l}\text { Observation } \\
\text { group }\end{array}$ & $2.81 \pm 0.74$ & $2.02 \pm 0.42$ & $1.39 \pm 0.52$ & $1.65 \pm 0.39$ & $1.46 \pm 0.52$ & $1.16 \pm 0.31$ & $4.65 \pm 0.97$ & $3.57 \pm 0.82$ \\
$\mathrm{t}$ & 0.262 & 2.011 & -0.266 & 1.781 & 0.281 & 2.083 & -0.129 & 2.546 \\
$\mathrm{p}$ & 0.397 & 0.024 & 0.396 & 0.039 & 0.389 & 0.020 & 0.449 & 0.006 \\
\hline
\end{tabular}

TABLE 2: COMPARISON OF IMT LEVELS BETWEEN THE TWO GROUPS OF PATIENTS BEFORE AND AFTER TREATMENT $(\mathrm{mm})$

\begin{tabular}{lccc}
\hline Group & Before therapy & $4 \mathrm{w}$ after treatment & $\mathbf{8} \mathrm{w}$ after treatment \\
\hline Control group & $1.23 \pm 0.08$ & $1.20 \pm 0.06$ & $1.17 \pm 0.13$ \\
Observation group & $1.25 \pm 0.10$ & $1.16 \pm 0.11$ & $1.10 \pm 0.11$ \\
$\mathrm{t}$ & -0.987 & 2.019 & 2.560 \\
$\mathrm{p}$ & 0.163 & 0.023 & 0.006 \\
\hline
\end{tabular}


TABLE 3: COMPARISON OF HMGB-1 AND YKL-40 LEVELS BEFORE AND AFTER TREATMENT IN THE TWO GROUPS

\begin{tabular}{lcccc}
\hline Group & \multicolumn{2}{c}{ HMGB-1 $(\mu \mathrm{g} / \mathrm{ml})$} & \multicolumn{2}{c}{ YKL-40 $(\mathrm{ng} / \mathrm{ml})$} \\
\cline { 2 - 5 } & Before therapy & After treatment & Before therapy & After treatment \\
\hline Control group & $4.72 \pm 1.01$ & $3.51 \pm 0.86$ & $68.92 \pm 5.12$ & $53.56 \pm 4.85$ \\
Observation group & $4.69 \pm 0.96$ & $1.64 \pm 0.79$ & $68.97 \pm 6.05$ & $35.97 \pm 4.18$ \\
$\mathrm{t}$ & 0.136 & 10.128 & -0.039 & 17.375 \\
$\mathrm{p}$ & 0.466 & $<0.001$ & 0.484 & $<0.001$ \\
\hline
\end{tabular}

TABLE 4: COMPARISON OF MYOCARDIAL ENZYME INDEXES BEFORE AND AFTER TREATMENT IN THE TWO GROUPS

\begin{tabular}{lcccc}
\hline Group & \multicolumn{2}{c}{ LDH (U/l) } & \multicolumn{2}{c}{ CK-MB (U/l) } \\
\cline { 2 - 5 } & Before therapy & After treatment & Before therapy & After treatment \\
\hline Control group & $152.34 \pm 9.23$ & $134.78 \pm 10.57$ & $78.45 \pm 6.19$ & $61.26 \pm 6.89$ \\
Observation group & $152.36 \pm 10.15$ & $120.95 \pm 11.28$ & $78.47 \pm 7.03$ & $53.18 \pm 5.27$ \\
$\mathrm{t}$ & 0.009 & 5.658 & 0.014 & 5.891 \\
$\mathrm{p}$ & 0.993 & $<0.001$ & 0.989 & $<0.001$ \\
\hline
\end{tabular}

Thrombus formation impairs the blood supply of the heart, leading to ischemia, hypoxic necrosis and the corresponding decline in nerve function, which is the pathological basis of CHD. CHD with carotid atherosclerosis is a complicated disease with a high clinical incidence. Preventing the occurrence of atherosclerosis is the main means to treat $\mathrm{CHD}^{[12]}$. The results of this study showed that after treatment, the levels of LDL-C, TG and TC in the observation group were lower than those in the control group, which was statistically significant, while HDL-C increased. It shows that atorvastatin combined with amlodipine can significantly reduce blood lipid levels. TC and LDL-C easily accumulate on the damaged vascular endothelium and promote the formation of atherosclerotic plaques ${ }^{[13]}$. HDL-C can promote the elimination of cholesterol and has a certain protective effect on the heart and brain ${ }^{[14]}$. Analysis of the results of this study: As a 3-Hydroxy-3Methyl-Glutaryl-Coenzyme A (HMG-CoA) reductase inhibitor, atorvastatin can inhibit the action of HMGCoA reductase, accelerate the metabolism of LDL-C, inhibit the production of $\mathrm{TC}$ and $\mathrm{TG}$, and increase the production of HDL-C. Atorvastatin has a good effect on lipid metabolism and anti-oxidative stress. Amlodipine is a dihydropyridine calcium channel blocker, which can regulate lipid anabolism at the gene level and reduce inflammation of the vascular endothelium. It hinders the proliferation and migration of vascular smooth muscle cells and cooperates with atorvastatin to play a lipid-lowering effect. The results of this study showed that before treatment, there was no difference in myocardial enzyme indexes between the two groups. After treatment, the LDH and CK-
MB levels of the two groups were lower than before treatment and the observation group was lower than the control group. It is suggested that amlodipine combined with atorvastatin can significantly improve the levels of myocardial enzymes in patients. After the addition of amlodipine, it has strong selectivity to blood vessels and can directly act on vascular smooth muscle, which has good application value.

The increase in IMT value indicates that more oxygen and nutrients need to be taken in the arteries, which requires the formation of a large number of blood vessels to meet the demand and the formation of a large number of blood vessels can promote the formation of atherosclerotic plaques ${ }^{[15]}$. The color Doppler ultrasound system can detect IMT and confirm the progress of arteriosclerosis, and to a certain extent can guide the diagnosis and treatment of carotid atherosclerosis and its complications ${ }^{[16]}$. The results of the study showed that there was no difference in IMT between the two groups of patients before treatment and the IMT values of the observation group were lower than those of the control group at 4 and $8 \mathrm{w}$ after treatment. The addition of amlodipine on the basis of atorvastatin can significantly improve the level of carotid artery intima in patients with CHD and carotid atherosclerosis. The reason for the analysis is that amlodipine reduces the lipid level, weakens the lipid peroxidation level of blood and aortic tissue, strengthens the role of superoxide dismutase and achieves a good effect of scavenging free radicals. It can also reduce endothelin-1 level to inhibit inflammation, reduce the proliferation of vascular smooth muscle cells and maintain the normal function of vascular 
endothelial cells. The combined use of the two drugs can enhance the anti-platelet aggregation function and protect the vascular endothelial function, and improve the carotid artery intima level.

HMGB-1 is an inflammatory factor that is closely related to vascular endothelial injury and there are few studies on it in the serum of patients with CHD and carotid atherosclerosis ${ }^{[17]}$. In this study, the reduction of HMGB-1 levels in the observation group was greater than that in the control group, which was statistically significant. It is suggested that amlodipine combined with atorvastatin can improve the level of HMGB-1. The reason for the analysis is: HMGB-1 can affect the function of smooth muscle cells and promote inflammation. Normal smooth muscle cells express less HMGB-1 than other cells. When cholesterol is deposited, smooth muscle cells are activated and secrete a large amount of HMGB-1. HMGB-1 can react with smooth muscle cells, which will generate more HMGB-1, promote inflammation and accelerate the formation of atherosclerosis. Atorvastatin can inhibit inflammation and improve endothelial cell function. After the observation group was given amlodipine, it regulated the qualitative synthesis and metabolism process by regulating the gene level and reduced the inflammatory response of the vascular endothelium. Amlodipine and atorvastatin had a synergistic lipidlowering effect. Reduce cholesterol damage to the arterial intima and reduce the expression of HMGB-1.

YKL-40 can accelerate the formation of branch blood vessels, thereby changing the morphology of vascular endothelial cells, thereby affecting their functions ${ }^{[18,19]}$. The level of YKL-40 in patients with CHD has a certain relationship with the severity of the disease. The results showed that the decrease of YKL-40 level in the observation group was greater than that in the control group, which was statistically significant. The reason for the analysis is atorvastatin has anti-inflammatory and hypolipidemic effects when used alone. Amlodipine not only has the effect of lowering blood pressure and blood lipids, but also has a coordinating effect in antioxidative stress and improving the release of nitric oxide. Amlodipine can better protect the function of endothelial cells and reduce the release of YKL-40.

Previous studies have shown that atorvastatin has a good therapeutic effect on CHD, but the effect is not ideal ${ }^{[20]}$. Long-term high-dose atorvastatin may damage the liver to a certain extent. Adding amlodipine to the treatment of atorvastatin has a significant lipid-lowering effect. Amlodipine has a long-acting effect. In addition, it also improves HMGB-1 and the level of YKL-40. These two indicators play an important role in the inflammatory response. Amlodipine is highly selective for diseased blood vessels. It can relax vascular smooth muscle and expand peripheral blood arteries, thereby increasing blood flow, preventing platelet aggregation and preventing the development of atherosclerosis.

In summary, amlodipine combined with atorvastatin has a good therapeutic effect on patients with CHD combined with carotid atherosclerosis, which can significantly improve the levels of blood lipids, HMGB1 and YKL-40 in patients and has good application value.

\section{Conflict of interests:}

The authors declared no conflict of interest.

\section{REFERENCES}

1. Bjørnestad EØ, Olset H, Dhar I, Løland K, Pedersen EK, Svingen GF, et al. Circulating trimethyllysine and risk of acute myocardial infarction in patients with suspected stable coronary heart disease. J Intern Med 2020;288(4):446-56.

2. Lam DH, Bell SM, Hira RS. Concomitant use of antiplatelets and anticoagulants in patients with coronary heart disease and atrial fibrillation: What do recent clinical trials teach us?. Curr Atheroscler Rep 2018;20(1):1-10.

3. Guaricci AI, Lorenzoni V, Guglielmo M, Mushtaq S, Muscogiuri G, Cademartiri F, et al. Prognostic relevance of subclinical coronary and carotid atherosclerosis in a diabetic and nondiabetic asymptomatic population. Clin Cardiol 2018;41(6):769-77.

4. Sahadevan M, Chee KH, Tai ML. Prevalence of extracranial carotid atherosclerosis in the patients with coronary artery disease in a tertiary hospital in Malaysia. Medicine 2019;98(15):e15082.

5. Golan R, Shai I, Gepner Y, Harman-Boehm I, Schwarzfuchs $\mathrm{D}$, Spence JD, et al. Effect of wine on carotid atherosclerosis in type 2 diabetes: a 2-year randomized controlled trial. Eur J Clin Nutr 2018;72(6):871-8.

6. Padoli P, Suwito J, Hariyanto T. Self-affirmation reduces the anxiety, $\mathrm{LDH}$ and troponin $\mathrm{I}$ in the clients with coronary heart disease (CHD). Jurnal Ners 2019;14(3):310-5.

7. Tao X, Sun M, Chen M, Ying R, Su W, Zhang J, et al. HMGB1modified mesenchymal stem cells attenuate radiationinduced vascular injury possibly via their high motility and facilitation of endothelial differentiation. Stem Cell Res Ther 2019;10(1):1-7.

8. Mathiasen AB, Harutyunyan MJ, Jørgensen E, Helqvist S, Ripa $\mathrm{R}$, Gøtze JP, et al. Plasma YKL-40 in relation to the degree of coronary artery disease in patients with stable ischemic heart disease. Scand J Clin Lab Invest 2011;71(5):439-47.

9. Luo P, Wang L, Zhu H, Du S, Wang G, Ding S. Impact of atorvastatin combined with ezetimibe for the treatment of carotid atherosclerosis in patients with coronary heart disease. Acta Cardiol Sin 2016;32(5):578-85.

10. Wang X, Li W, Song F, Wang L, Fu Q, Cao S, et al. Carotid atherosclerosis detected by ultrasonography: A national CrossSectional study. J Am Heart Assoc 2018;7(8):e008701.

11. Vigen $T$, Ihle-Hansen $H$, Lyngbakken $M N$, Berge $T$, 
Thommessen B, Ihle-Hansen $\mathrm{H}$, et al. Blood pressure at age 40 predicts carotid atherosclerosis two decades later: Data from the Akershus Cardiac Examination 1950 Study. J Hypertens 2019;37(10):1982-90.

12. Yamamoto H, Nakajima $T$, Kawahara R, Nakabo S, Hashimoto $\mathrm{M}$, Yamamoto $\mathrm{W}$, et al. Evaluation of risk factors for atherosclerosis using carotid ultrasonography in Japanese patients with rheumatoid arthritis. Int J Rheum Dis 2019;22(7):1312-8.

13. Kristiansen $\mathrm{O}$, Vethe NT, Fagerland MW, Bergan S, Munkhaugen J, Husebye E. A novel direct method to determine adherence to atorvastatin therapy in patients with coronary heart disease. Br J Clin Pharmacol 2019;85(12):2878-85.

14. Roth L, Van der Donckt C, Veseli BE, Van Dam D, De Deyn PP, Martinet W, et al. Nitric oxide donor molsidomine favors features of atherosclerotic plaque stability and reduces myocardial infarction in mice. Vascul Pharmacol 2019;118:106561.

15. Gao W, Cui H, Li Q, Hai Z, Jingjing Y, Ping L, et al. Upregulation of microRNA8 reduces cardiac microvascular endothelial cells injury induced by coronary artery disease through the inhibition of HMGB1. Journal of Cellular Physiology, 2019, 235(3):3079-95.

16. Abdelnabi M, Almaghraby A, Tok OO, Oz TK, Saleh Y, Morsi A, et al. A real-life correlation between clinical SYNTAX score II and carotid intima-media thickness in patients with stable coronary artery disease. J Saudi Heart Assoc 2020;32(1):8-11.
17. Yang L, Dong $\mathrm{H}, \mathrm{Lu} \mathrm{H}$, Liao $\mathrm{Y}$, Zhang $\mathrm{H}, \mathrm{Xu} \mathrm{L}$, et al. Serum YKL-40 predicts long-term outcome in patients undergoing primary percutaneous coronary intervention for ST-segment elevation myocardial infarction. Medicine 2019;98(12):e14920.

18. Kajikawa Y, Ikeda M, Takemoto S, Tomoda J, Ohmaru N, Kusachi S. Association of circulating levels of leptin and adiponectin with metabolic syndrome and coronary heart disease in patients with various coronary risk factors. Int Heart J 2011;52(1):17-22.

19. Xing Y, Guo J, Gai L, Liu B, Luo D. Serum YKL-40 is associated with the severity of coronary artery disease and hypertension. Asian J Surg 2020;43(11):1121-2.

20. Turgeon RD, Althouse AD. Inappropriate inclusion of multiple studies in a meta-analysis of randomized controlled trials of atorvastatin loading prior to percutaneous coronary intervention for acute coronary syndrome. Eur Heart J 2019;6(11):11-16.

This is an open access article distributed under the terms of the Creative Commons Attribution-NonCommercial-ShareAlike 3.0 License, which allows others to remix, tweak, and build upon the work non-commercially, as long as the author is credited and the new creations are licensed under the identical terms

This article was originally published in a special issue, "Novel Therapeutic Approaches in Biomedicine and Pharmaceutical Sciences" Indian J Pharm Sci 2021:83(6) Spl Issue "174-179" 